\title{
Entrepreneurial Competencies of Women Entrepreneurs of Micro and Small Enterprises
}

\author{
Käthe Schneider \\ Faculty of Social and Behavioural Sciences, Friedrich-Schiller-University of Jena, Jena, Germany
}

Email address:

k.schneider@uni-jena.de

\section{To cite this article:}

Käthe Schneider. Entrepreneurial Competencies of Women Entrepreneurs of Micro and Small Enterprises. Science Journal of Education. Vol. 5, No. 6, 2017, pp. 252-261. doi: 10.11648/j.sjedu.20170506.14

Received: October 20, 2017; Accepted: November 2, 2017; Published: December 20, 2017

\begin{abstract}
Entrepreneurial competencies are critical for entrepreneurial success. Despite a growing body of literature in the field of entrepreneurial competencies, there is still considerable uncertainty concerning entrepreneurial competencies of female entrepreneurs. The objective of the study is therefore to empirically analyze the entrepreneurial competencies of female entrepreneurs. Based on a study of 306 women entrepreneurs of Micro and Small Enterprises (200 women entrepreneurs from Germany and 106 women entrepreneurs from Ireland), this analysis finds that entrepreneurial competencies as a higher order latent construct have a major impact on entrepreneurial success. Entrepreneurial competencies of women entrepreneurs in Germany and Ireland can be operationalized by a set of six first-order factors, including functional task related managerial skills, entrepreneurial characteristic adaptations of self-efficacy and orientations of competition, risk-taking and innovation, and the founder and innovator identity. The theoretical construct of entrepreneurial performance, which consists of the dimensions of economic, individual and societal performance, is expanded with the dimensions of performance quality, customer satisfaction and productivity. The practical implication of the study is that not only task related skills, but also distal personality related characteristic adaptations and identity should be developed in entrepreneurial learning programs targeted at women entrepreneurs who start small businesses. Future studies need to isolate the influence of context from the identified competencies.
\end{abstract}

Keywords: Women's Entrepreneurship, Female Entrepreneurship, Women Entrepreneurs, Entrepreneurial Competencies, Entrepreneurial Performance

\section{Introduction and Problem Statement}

Scientific interest in the identification of entrepreneurial competencies has increased in recent years [13,33]. Research on competencies is connected with the pedagogical aim of furthering competencies and improving performance [32]. Entrepreneurship should contribute to maintaining existing and creating new jobs, as is postulated, for example, in the frame of the Europe 2020 Strategy [14]. Thereby the concept of sustainability receives a key function, since it should enduringly contribute to economic, cultural, social as well as ecological improvements and to entrepreneurial success. Entrepreneurial success, which contributes to maintaining present and creating new jobs, and testifies to competence in facing the demands of societal and technological change, is determined by numerous factors, such as, e.g., socio-cultural and economic factors, but also by education and training
[34]. The need for support of entrepreneurs in the form of continuing education is seen, e.g., in "that only $46 \%$ of products introduced to the market are considered successful" [29 p. 400]. An understanding of the personal factors that explain entrepreneurial performance and that can be influenced by learning is of interest for research on further education. Total Early Entrepreneurial Activity rate (TEA) is a key indicator of the level of new enterprise creation and includes persons in the process of starting and running a new business before the background of the established business cycle (three-and-a-half years). TEA rates for women in innovation-driven European economies are, with $5 \%$ of the adult population, lower than, for example, in developing regions of Asia (13\%) or the United States (10\%) [20].

Gottschalk and Niefert [17] have recently studied the 
gender differences in business success of German start-up firms. They analyzed the business performance of about 4,700 German start-up firms within a maximum period of four years after their foundation, based on data from the KfW/ZEW Start-Up Panel. Sales, employment growth, and return on sales were used as business performance indicators. Gottschalk and Niefert [17] found that compared to maleowned companies women-owned firms underperform. The performance difference might be explained by gender differences in personal and firm characteristics and by gendered resources and conditions for entrepreneurship. Differences in founders' human capital explain a considerable part of the variance in employment growth and sales, whereas, however, the contribution of the experience variable is greater than that of formal academic training. Gottschalk and Niefert [17] show that the profitability gap becomes larger when accounting for gender differences in entrepreneurial experience. They do not find gender differences in profit orientation but find that female entrepreneurs are less growth-oriented.

Hence, women's entrepreneurship should be supported because there is a need to increase the number of women entrepreneurs and raise their performance and growth potential. To foster women's entrepreneurship we will focus on entrepreneurial performance. In facilitating the entrepreneurial performance of women entrepreneurs, education plays a key role. To design educational programs that facilitate women entrepreneurs' success, a better understanding of the competencies that facilitate women's entrepreneurial success is needed. Because the current understanding of entrepreneurial competencies of women entrepreneurs as predictors of entrepreneurial success may be incomplete, it would be difficult to design an effective learning program for entrepreneurial development of women entrepreneurs. The objective of the study is therefore to empirically analyze the entrepreneurial competencies of female entrepreneurs based on a review of current theory and available evidence. For this purpose, a model of competencies has been developed that predict entrepreneurial success of women entrepreneurs as an essential contribution to constructing more effective training programs and optimizing the selection of women entrepreneurs.

Because Germany and Ireland are among the innovationdriven European economies with relatively low female TEA rates (Germany: 3,29\% of the female population between 1865 years; Ireland 5,76\%) [20], the entrepreneurial competencies of women entrepreneurs in Germany and Ireland will be examined. This research should increase the understanding of how to develop targeted developmental and educational programs for women entrepreneurs.

\section{Literature Review and Theory}

Many studies on the personal factors of entrepreneurial success employ the concept of competence. Although there are several approaches to competence, there is "no single common conceptual framework" [47 p. 46]. Besides the variety of meanings of competence, there are also two different concepts in Britain and America, competence in Britain and competency in America [32]. While competence refers to behavior a person should be able to demonstrate [e.g. 11], competency is defined as an underlying set of personal characteristics that facilitate superior performance [e.g. 7,6]

Competencies as "theoretical constructs" [38 p. 8] are understood in the following discussion as personal characteristics or prerequisites for meeting specific demands of performance [32, 47]. Referring to the OECD/EUROSTAT framework for Entrepreneurship Indicators which consists of the components determinants, performance and impact the determinants are related in our case to the personal factors, and the performance to the entrepreneurial performance, such as, e.g. economic performance of the enterprise. "Impacts ... reflect the 'value' created by entrepreneurs and entrepreneurship. ... this value can be manifested in a number of ways, for example a macroeconomic variable like GDP growth or employment ..." [1 p. 6-7].

There are different approaches to categorizing personal characteristics: Bartlett and Ghoshal [3] suggest the three categories of attitudes/traits, knowledge/experience, and skills/abilities. Stuart and Lindsay [43] also defined competencies as a person's skills, knowledge, and personal traits. Boyatzis [7] develops a model of competencies that includes three levels: motives and traits; social role and selfconcept; and, role transitions. Comparing the characteristics focused on in different studies, it is evident that they include categories such as knowledge, attitudes, motives, skills, and traits [35] or cognitive, emotional, motivational, social, and behavioral components [38].

In the following studies drawing on these categories of personal characteristics will be presented. Much research has been devoted to modeling entrepreneurial characteristics as clusters of skills [e.g. 4, 25]. Studies show that task-related skills enable better results than non-task-related skills: "Human capital leads to higher performance only if it is applied and successfully transferred to the specific tasks that need to be performed" [44 p. 344]. Skills strongly predict success if they are related both to processes and daily tasks engaged in by entrepreneurs, as well as to the overall content of their business [44]. In terms of context, the strength of this relation is not influenced by the industrial or commercial sector, but it seems that the success relationship is stronger for newer businesses than for older ones [44]. This relationship points to the importance of education in promoting entrepreneurial and domain specific skills of early stage entrepreneurs.

That not only task-related skills but also ability to monitor one's own and others' feelings and emotions, to discriminate among them and to use this information to guide one's thinking and actions [39 p. 189] is related to entrepreneurial success was shown by a study which tested entrepreneurs' emotional intelligence: McLaughlin [28] found in a study of 609 entrepreneurs from various different US based firms that the overall measure of emotional intelligence showed a 
significant, positive correlation with financial entrepreneurial success, performance relative to competitors and subjective perceptions of satisfaction with entrepreneurial performance. A mediator that accounts for the relationship between emotional intelligence and each of the three dimensions of entrepreneurial success is managerial competencies [28]. This applies as well to the entrepreneurial competencies that serve as a mediator between emotional intelligence and each of the three components of entrepreneurial success [28].

Studies examining personality traits have also shown their influence on entrepreneurial success [8, 22, 37]. In a metaanalysis, Brandstätter [8] assessed the correlation between personality traits and entrepreneurial behavior. He explored the personality traits of entrepreneurs by comparing entrepreneurs' personality trait scores with the scores of managers. As a result, Brandstätter [8] suggests viewing the entrepreneurial personality as different from that of the manager. Entrepreneurs are more open to new experiences (openness), more dutiful (conscientiousness) and rather energetic towards the social and material world (extraversion) compared to managers. Furthermore, entrepreneurs seem to score lower in agreeableness and neuroticism than managers. Leutner, Ahmetoglu, Akhtar, \& Chamorro-Premuzic [22] found that very specific personality traits such as being visionary, proactive or creative are stronger predictors of entrepreneurial success compared to the so-called Big Five Factors. Traits matched to entrepreneurial tasks have more impact on success than broad, encompassing ones. The importance of the personality for entrepreneurial success has been shown in numerous studies [cf. e.g. 16, 24, 33, 37]: Thus, for example, Göbel [16] was able to show that persons who display high selfefficacy, high need for dominance and marked internal locus of control are as much as $89 \%$ successful as entrepreneurs, while persons with low levels of these variables are successful only to $1.1 \%$. Less stable and more specific dimensions of the personality, as for example, the orientation of enjoying innovation, are likewise positively associated with entrepreneurial success. Studies reveal that entrepreneurial behavior, such as business creation, and business success, is related to need for achievement, generalized self-efficacy, innovativeness, ability to cope with stress, need for autonomy and proactive personality [37].

Personality exerts not only direct influence on entrepreneurial success, but also has indirect effects on success via knowledge and experience. Moreover, depending on personality differences, acquired knowledge has various effects [16]: While entrepreneurs with high self-efficacy, for example, with the strategy of personnel furthering, are successful, for those more prone to mistakes, a strategy of detailed and good planning is relevant for success in starting enterprises [16]. Many studies focus on both personality and skills as underlying characteristics of entrepreneurial competencies: For example, Peris Bonet, Rueda Armengot, and Galindo Martín [33] aim at elaborating a model based on attributes of an entrepreneur and qualifications to predict entrepreneurial success in Europe. A sample was made of family owned companies in different industrial settings operating in the European Union and characterized as independent (non-subsidiary), and as innovative small and medium-sized enterprises (SME). The firms had to have been operating for at least five years. From a universe of 10,000 European companies, 2,894 SMEs (28.94 percent) were analyzed. Regarding the entrepreneur's self-assessed characteristics, self-confidence and initiative are the entrepreneur's most characteristic attributes (with an average of 8 out of 10), followed by dynamism and leadership (with 8.4 ), perseverance (8.2), creativity and energy (both with 8.1 ), receptivity (7.9) and ability to get along with other people (7.5) [33]. Makhbul and Hasan [24] investigated the relationship between entrepreneurial characteristics and entrepreneurial success in an Asian region. 163 owners or entrepreneurs of SMEs in West Malaysia with at least three years of business operations answered a self-monitored survey questionnaire. The most significant factor affecting entrepreneurial success is the religious duty/honesty factor followed by communication skills and strong will on the part of entrepreneurs. In this study, a successful business is defined as a venture that has been operating for at least three years.

While there is increasing interest in entrepreneurial competencies, there are only a few studies [e.g. 21, 31] addressing female entrepreneurs. Mitchelmore and Rowley [31] analyzed the competencies of female entrepreneurs in England and Wales based on a convenience sample of 210 women entrepreneurs. Factor analysis was used to determine the factors of the self-reported relevant entrepreneurial competencies of women entrepreneurs and to identify subcompetencies that loaded on the key factors [31]. The authors identified four factors of self-rated relevant entrepreneurial competencies: (1) personal and relationship competencies; (2) business and management competencies; (3) entrepreneurial competencies; and (4) human relations competencies [31].

Despite this study and a growing body of literature in the field of entrepreneurial competencies, it seems that there is still considerable uncertainty concerning competencies as a set of characteristics of female entrepreneurs that results in effective performance [e.g. 9, 32]. Studies are thus needed that can offer more insight into entrepreneurial competencies of women entrepreneurs. In this study, the scope of research on the theoretical construct of entrepreneurial competencies will be widened by including components that are prerequisites for women entrepreneurs to meet specific demands: First, as prerequisites the skills of women entrepreneurs that explain entrepreneurial performance will be analyzed. Skills as a component of the set of characteristics are always learned and are related to the fact to think in particular ways [42]. Second, and besides skills, a set of personality related characteristics will be studied using a theoretical model of personality. From the presently available personality models, it will be drawn on that of McAdams and Pals [27], which is highly regarded and widely used. Third, the impact of skills and personal 
characteristics on the entrepreneurial performance of female entrepreneurs is measured.

The McAdams and Pals personality model [27] comprehends the personality levels (1) dispositional traits, (2) characteristic adaptations and (3) life narrative. The level of dispositional characteristics relates to comparable dimensions of persons. Traits are relatively stable, situationtranscending personal characteristics. They include traits such as openness, conscientiousness, extraversion, agreeableness, or neuroticism. Characteristic adaptations on the second level of the personality model describe contextdependent behavioral tendencies and represent how people based on their traits typically master various different challenges. In contrast to dispositional characteristics, characteristic adaptations display greater specificity and a lower degree of stability [cf. 16]. Examples of characteristic adaptations are self-efficacy or orientations. Life histories on the third level of the personality model refer to constructions of the personality that give life meaning. On this level a person poses the question of the identity that brings the individualized to expression: "Who am I?" or "Who do I want to be?" [27]. The personality model was supplemented with two further levels, that of evolution and human nature, as well as that of culture. The former refer to universals conditioned by evolution that characterize people and the latter to meaning systems and practices. Culture exerts different influences on the levels of personality: It has a moderate effect on the phenotypic expression of characteristics, a stronger effect on characteristic adaptations and a very strong influence on life history [27]. As categories of personality-related sets of components, characteristic adaptations and identity will be addressed in this study. Entrepreneurial orientation and entrepreneurial self-efficacy stand for characteristic adaptations that will be analyzed. Traits will not be studied, because they have limited learning potential.

\section{Method}

\subsection{Participants}

The study population consisted of early and established women entrepreneurs from Ireland and Germany, operationalized as enterprise owners with at least one employee. A total of 306 participants (200 women entrepreneurs from Germany and 106 women entrepreneurs from Ireland) were recruited for this study. Questionnaires were distributed to a convenience sample to elicit a sufficient level of response. A total of $36 \%$ of the women entrepreneurs are early stage entrepreneurs, and 64\% established women entrepreneurs. The mean age of this group was 44 years, ranging from 23 to 70 years. A total of $8 \%$ of participants have a secondary school degree, 39\% a Bachelor degree, $45 \%$ are college graduates, and $8 \%$ have a $\mathrm{PhD}$. The entrepreneurs have no more than 16 employees (mean number: 5 employees). The study focuses on micro- $(<10$ employees) and small enterprises (SE) $(<50$ employees) which are assumed to be more innovative than larger companies.

\subsection{Measures}

\subsubsection{Functional Managerial Skills}

Self-assessed functional skills refer to skills a manager is supposed to have acquired, such as skills of general marketing, sales strategies and financial planning. It is assumed that a successful female entrepreneur also needs functional skills. The functional skills were measured using a twenty item scale adapted from the EU Project Entrepreneurial Learning Training Needs Analysis for SMEs [18]. Answers are given on a five point Likert scale ranging from 'low competence' to 'high competence'.

\subsubsection{Characteristic Adaptation of Entrepreneurial Self-Efficacy}

Self-efficacy is a construct of Bandura's social cognitive theory which describes the confidence in one's abilities to perform the target behavior [2]. Entrepreneurial self-efficacy, that can be regarded as a characteristic adaptation, measures the self-confidence that individuals, here women entrepreneurs, have regarding their ability to successfully perform the entrepreneurial behavior. The scale has one dimension [48]. Four items (e.g. 'I can recognize business opportunities') are measured on a seven point Likert scale ranging from no confidence to complete confidence. The dimension was measured by demonstrated adequate reliability (Cronbach's alpha $=0.78)[48]$.

\subsubsection{Characteristic Adaptation of Entrepreneurial Orientation}

The construct of entrepreneurial orientation represents a firm's degree of entrepreneurship [30], referring to "processes, practices and decision-making activities that lead to new entry" [23]. Because most of the companies in the sample are micro-enterprises with fewer than four employees, it is likely that in most cases the firm is highly represented by the women entrepreneur. For this reason, entrepreneurial orientation can be regarded as the extent of applied entrepreneurial processes, practices and decisionmaking activities by women entrepreneurs.

Entrepreneurial orientation is a higher-order latent construct consisting of four first-order factors measured by eleven items [46]. The dimensions are market proactiveness (PR) (e.g. 'In the past three years, my organization has marketed a large variety of new lines of products or services'), risk-taking (RK) (e.g. 'In general, my organization has a strong propensity for high risk projects (with chances of very high returns'); competitive aggressiveness (AG) (e.g. 'In dealing with competitors, my organization often leads the competition, initiating actions to which our competitors have to respond'), and firm innovativeness (IN) (e.g. 'Management actively responds to the adoption of "new ways of doing things" by main competitors') [46]. Items are measured on a five point Likert scale ranging from 'strongly disagree' to 'strongly agree". Scores are obtained for each dimension. All 
dimensions demonstrated high reliability [46]. The measurement model resulted in a good fit: $\chi^{2}=79.771$, $\mathrm{df}=40, \mathrm{p}=0.000, \chi 2 / \mathrm{df}=1.994, \mathrm{GFI}=0.938, \mathrm{CFI}=0.960$ [46]. The first-order loadings ranged from 0.52 to $0.93(\mathrm{t}>1.96$, $\mathrm{p}<0.001$ ), the second-order loadings from 0.60 to 0.99 $(\mathrm{t}>1.96, \mathrm{p}<0.001)$ [46].

\subsubsection{Entrepreneurial Identity}

Entrepreneurial identity relates to the questions "Which entrepreneur am I?" und "Which entrepreneur do I want to be?" and is measured in its complexity.

Identity complexity refers to the diversity and richness of role perception [36], here to an entrepreneur's work-roles. According to Poudel [36], entrepreneurial identity consists of the following roles: founder identity, innovator identity, leader identity, professional identity, and manager identity [36]. Each role will be assessed by women entrepreneurs.

\subsubsection{Entrepreneurial Performance}

Individual differences in overall entrepreneurial performance were measured with fourteen items. The dimensions of overall entrepreneurial performance are:

1. an economic dimension including global performance of firms in terms of employees, sales and profit growth, market share,

2. a dimension of individual performance with personal satisfaction, provided self-esteem, self-confidence, personal life quality, enhancement of family relationship and of emotional-affective relationships, and

3. a societal performance including enhancement of social relationships, public visibility, and contribution to society.

The dimensions are measured with items validated by Valencia-Silva, Lamolla, and Amorós [45]. The factors of economic performance (4 items), social performance (5 items), and individual performance ( 7 items) had good internal consistency [45]: The Cronbach's alphas for the constructs were 0.866 for economic performance, 0.871 for individual performance and 0.703 for the societal performance. The dimension of organizational efficacy was added to the success model, consisting of quality performance, customer satisfaction, loyalty, and productivity.

\subsection{Procedure}

Data for the study were gathered using a structured webquestionnaire. Completion of the questionnaire required about 20 minutes. A convenience sampling technique was used to construct the samples in Germany and Ireland. This technique was useful because it was hard to achieve a reasonable sample size. Participants were recruited by contacts with women entrepreneur associations, (e.g. Enterprise Ireland in Ireland and VdU in Germany), through social media Internet sites, emails, posts in relevant forums and attending a women entrepreneurs conference. The questionnaire consists of three parts: The first part includes a comprehensive personal and organizational background questionnaire (e.g. age, years of business experience, qualifications, motivation, commercial/industrial branch, number of employees). The second part covers functional managerial skills, questions related to entrepreneurial identity, entrepreneurial self-efficacy, entrepreneurial orientation, and entrepreneurial performance. Most questions were closed-ended and were designed using a Likert scale. The last part of the questionnaire was a sentence completion test. Sentence stems were to be completed, but the results of this test are not reported here. Initially the questionnaire was designed in English, based on existing scales and tests adapted from other studies. The questionnaire was translated into German and then distributed to 10 sample respondents to check whether the desired information was obtained or not, as a pre-test. Based on this, translations of some items were modified.

\section{Results and Discussion}

Descriptive statistics are presented in Table 1. The data analysis of this study follows a two-step procedure: assessing measurement models using exploratory factor analysis (EFA; Geomin-Rotation), followed by assessing path relationships using structural equation modeling (SEM; MPLUS-Software) [15]. Using SEM it is possible to model measured and latent theoretical variables simultaneously.

Table 1. Value range, sample size $(N)$, mean $(M)$ and standard deviation (SD) of manifest survey parameters.

\begin{tabular}{|c|c|c|c|c|}
\hline Dimension & Value range & $N$ & $M$ & $S D$ \\
\hline Identity Complexity: Founder \& Innovator & $\begin{array}{l}0 \text { ("'not at all important")- } \\
4 \text { ("extremely important”) }\end{array}$ & 304 & 2.74 & 1.03 \\
\hline Functional Managerial Skills & $\begin{array}{l}1 \text { ("very low competence") - } \\
5 \text { ("high competence") }\end{array}$ & 306 & 3.71 & 0.70 \\
\hline Entrepreneurial Orientation: Innovation & $\begin{array}{l}1 \text { ("strongly disagree") - } \\
5 \text { ("strongly agree") }\end{array}$ & 306 & 4.33 & 0.74 \\
\hline Entrepreneurial Orientation: Competition & $\begin{array}{l}1 \text { ("strongly disagree") - } \\
5 \text { ("strongly agree") }\end{array}$ & 306 & 3.31 & 0.97 \\
\hline Entrepreneurial Orientation: Risk Taking & $\begin{array}{l}1 \text { ("strongly disagree") - } \\
5 \text { ("strongly agree") }\end{array}$ & 306 & 2.78 & 1.02 \\
\hline Entrepreneurial Self-Efficacy & $\begin{array}{l}1 \text { ("no confidence") - } \\
7 \text { ("complete confidence") }\end{array}$ & 306 & 5.79 & 1.05 \\
\hline Quality Performance & $\begin{array}{l}1 \text { ("strongly disagree") - } \\
6 \text { ("strongly agree") }\end{array}$ & 304 & 4.01 & 1.14 \\
\hline Customer Satisfaction & 1 ("strongly disagree") - & 303 & 5.12 & 0.86 \\
\hline
\end{tabular}




\begin{tabular}{|c|c|c|c|c|}
\hline Dimension & Value range & $N$ & $M$ & $S D$ \\
\hline Productivity & $\begin{array}{l}6 \text { ("strongly agree") } \\
1 \text { ("strongly disagree") - } \\
6 \text { ("strongly agree") }\end{array}$ & 304 & 4.15 & 1.18 \\
\hline Economic Performance & $\begin{array}{l}1 \text { ("decreasing significantly") - } \\
5 \text { ("increasing significantly") }\end{array}$ & 306 & 3.37 & 0.87 \\
\hline Individual Performance & $\begin{array}{l}1 \text { ("decreasing significantly") - } \\
5 \text { ("increasing significantly") }\end{array}$ & 306 & 3.18 & 1.16 \\
\hline Social Performance & $\begin{array}{l}1 \text { ("decreasing significantly") - } \\
5 \text { ("increasing significantly") }\end{array}$ & 306 & 3.81 & 0.91 \\
\hline
\end{tabular}

Model structure was developed above all on the foundation of explorative factor analysis to individual scales and modification indices. These modification indices show directly which items are critical for model fit and the extent to which exclusion improves this fit $[15,19]$.

The model's goodness of fit was assessed using the $\chi^{2-}$ statistic, comparative fit index (CFI), Root Mean Square Error of Approximation (RMSEA) and Standardized Root Mean Square Residual (SRMR) [5, 15].

Included in the model explaining women entrepreneurs' entrepreneurial success based on factors that can be acquired by learning and development as independent factors were functional managerial skills, characteristic adaptations of entrepreneurial self-efficacy and of entrepreneurial orientation and complexity of entrepreneurial identity; the factor to be explained is entrepreneurial performance.

The SEM model in this study, consisting of two latent constructs (i.e. entrepreneurial competencies (EC) and entrepreneurial performance (EP)), resulted in an adequate fit. The model is presented in Figure 1. Functional managerial skills, complexity of entrepreneurial identity of founder and innovator, entrepreneurial orientations of competition, risk-taking and innovation, and entrepreneurial self-efficacy predict the latent total factor labelled as entrepreneurial competencies, which is a predictor of entrepreneurial performance. For the sample employed, the following fit indices were obtained (Table 2):

Table 2. Fit indexes of the model.

\begin{tabular}{llll}
\hline $\boldsymbol{\chi}^{2}(\boldsymbol{d} \boldsymbol{f})$ & RMSEA & CFI & SRMR \\
\hline $866(481) ; p<.05$ & .051 & .897 & .069 \\
\hline
\end{tabular}

Notes. $d f=$ degree of freedom; $p=$ two-sided significance level). $R M S E A=$ Root Mean Square Error of Approximation; $C F I=$ comparative fit index; $S R M R=$ Standardized Root Mean Square Residual.

According to Geiser [15], an acceptable model-fit is characterized by RMSEA $\leq .08$, SRMR $\leq .08$ and CFI $\geq .95$. The criteria from the model are in the domain of 'satisfactory' model agreement (RMSEA $<=.08$ and SRMR $<=.08$; [15]. The CFI-Cut-Off of.897 almost reaches the value of.9 which is acceptable for questionnaire based research according to Marsh, Hau, and Grayson [26, 5]. The CFI as a measure of incremental fit states that the model in our case is able to explain $89.7 \%$ more than a "zero model" (no correlation of variables) with no information.

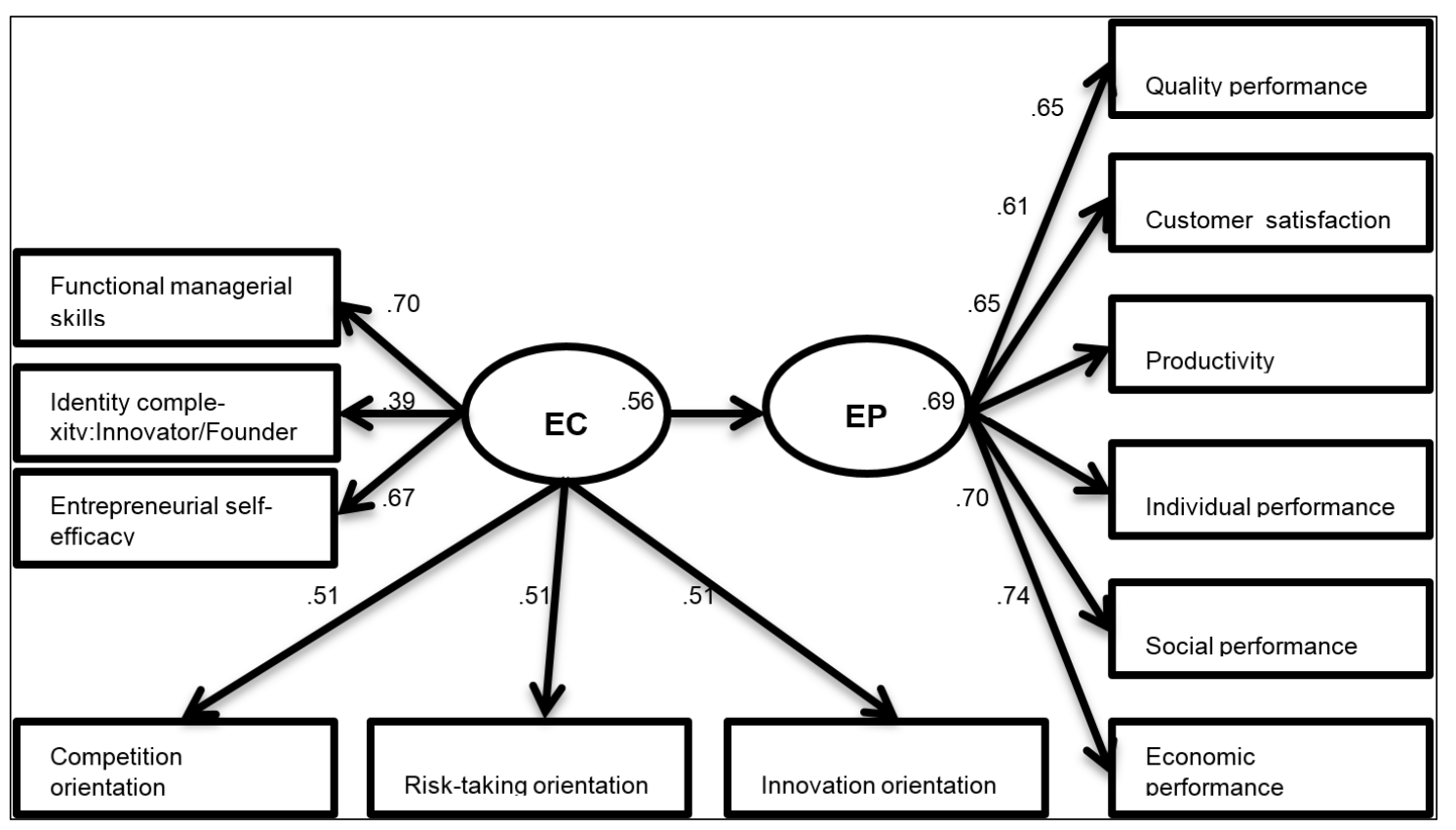

Figure 1. Structural Equation Model.

The factor "entrepreneurial competencies" (EC) is a significant predictor of "entrepreneurial performance" (EP)
$(=.559 ; \mathrm{p} \leq .001)$. The best predictor of entrepreneurial competencies is the factor of functional managerial skills 
$(=.703 ; \mathrm{p} \leq .001)$. Entrepreneurial self-efficacy was the second strongest predictor of entrepreneurial competencies $(=.667$; $\mathrm{p} \leq .001)$. The richness of perception of the entrepreneurial role operationalized by identity of founder and identity of innovator predicts $(=.385 ; \quad \mathrm{p} \leq .001)$ entrepreneurial competencies. For each of three entrepreneurial orientation factors the impact is still strong and nearly the same, ranging from $(=.505 ; \mathrm{p} \leq .001)$ to $(=.510 ; \mathrm{p} \leq .001)$. This model confirms the dimensions of entrepreneurial performance (Table 3). consisting of economic, societal, and individual performance. The added effectiveness dimensions of quality of performance, customer satisfaction and productivity loaded as well on the factor of entrepreneurial performance. The dimension of loyalty does not predict entrepreneurial success in the model.

Table 3. Factor of entrepreneurial performance.

\begin{tabular}{llll}
\hline Regressor & $\boldsymbol{A}$ & $\boldsymbol{S} \boldsymbol{E}$ & $\boldsymbol{p}$ \\
\hline 1. Quality Performance & 0.654 & 0.061 & 0.000 \\
2. Customer Satisfaction & 0.604 & 0.056 & 0.000 \\
3. Productivity & 0.650 & 0.056 & 0.000 \\
4. Economic Performance & 0.741 & 0.042 & 0.000 \\
5. Individual Performance & 0.689 & 0.043 & 0.000 \\
6. Social Perfomance & 0.702 & 0.051 & 0.000 \\
\hline
\end{tabular}

Notes. Factor loadings $(\lambda)$, Standard error $(S E)$ and two-sided significance level $(p)$.

In the model, economic performance is measured by sales $(=.863 ; \mathrm{p} \leq .001)$, profits $(=.863 ; \mathrm{p} \leq .001)$, market share $(=.697 ; \mathrm{p} \leq .001)$, and offered products and services $(=.495$; $\mathrm{p} \leq .001)$. The dimension of individual performance consists in enhancing your family relationship (=.937; $\mathrm{p} \leq .001)$, enhancing your emotional-affective relationships $(=.899$; $\mathrm{p} \leq .001)$ and reconciling your professional and personal life $(=.747 ; \mathrm{p} \leq .001)$. The social performance is explained by providing public visibility $(=.879 ; \mathrm{p} \leq .001)$ and contributing to society $(=.681 ; \mathrm{p} \leq .001)$. Entrepreneurial orientation is no higher-order latent construct anymore. Rather, in the model three first-order factors, orientation of competition, orientation of risk-taking, and orientation of innovation, exert direct influence on entrepreneurial competencies. The first order factor of entrepreneurial self-efficacy is predicted by the indicators of self-efficacy of recognizing business opportunities $(=.729 ; \mathrm{p} \leq .001)$, creating and developing new products and services $(=.728 ; \mathrm{p} \leq .001)$ and thinking in creative ways to solve problems $(=.680 ; \mathrm{p} \leq .001)$.

The following task-related skills load on the first order factor of functional skills: know and manage technological changes $(=.681 ; \mathrm{p} \leq .001)$, manage changes in production or market needs $(=.448 ; \mathrm{p} \leq .001)$, increase production/service request $(=.647 ; \mathrm{p} \leq .001)$, manage general marketing strategies $(=.596 ; \mathrm{p} \leq .001)$, improve quality $(=.584 ; \mathrm{p} \leq .001)$, manage increases in customer/consumer complaints $(=.569 ; \mathrm{p} \leq .001)$, and deal with increases in competition $(=.689 ; \mathrm{p} \leq .001)$.

Taking into account the covariates of age and education, the model does not show any significant changes of structures of loadings.
The goal of this study was to examine person-related factors that can be acquired through learning and development and that explain entrepreneurial performance of women entrepreneurs in the innovation driven economies of Germany and Ireland. In the model, the factor of entrepreneurial competencies has a considerable influence on entrepreneurial success. The results reveal that the factor of entrepreneurial competencies is a higher order latent construct which can be operationalized by a set of six first order factors, including functional managerial skills, entrepreneurial characteristic adaptations of self-efficacy and of orientations of competition, risk-taking and innovation, and the founder and innovator identity. The theoretical construct of entrepreneurial performance consisting of the dimensions of economic performance, individual performance and societal contribution is enhanced by the dimensions of quality of performance, customer satisfaction and productivity.

Both skills and broader factors of characteristic adaptations and identity strongly predict entrepreneurial competencies, though skills do so more consistently. The identified functional managerial skills are task related. High entrepreneurial performance of women entrepreneurs can be achieved by acquiring task related managerial skills and applying them in a competitive, risk-taking and innovative way to the firm, while developing entrepreneurial selfefficacy and the identity of a founder and innovator. Acquiring entrepreneurial competencies can be understood as applying functional skills to business in a competitive, risktaking and innovative way if self-efficacy and identity are developed. The applications and orientations lead to developing an entrepreneurial firm. According to Miller [30 p.771], an “... entrepreneurial firm is one that engages in product-market innovation, undertakes somewhat risky ventures, and is first to come up with 'proactive' innovations, beating competitors to the punch."

The study is based on a theoretical model of person-related factors and is one of the few studies including task relating skills: Unger, Rauch, Frese and Rosenbusch [44] showed in a meta-analysis that of 70 studies, only eighteen addressed task-related skills.

The research results showed that the factor of entrepreneurial competencies is a theoretical construct that includes clusters of skills, characteristic adaptations and identity. In the model, all factors are constructs of the same order, and none is an underlying factor of the others. Surprisingly, distal person-related variables like identity interact significantly with entrepreneurial competencies on the same level as task related skills.

This study informs the program design about which competencies should be furthered to enhance entrepreneurial success [40]. Program goals need to refer to entrepreneurial capabilities, characteristic adaptations of personal entrepreneurial self-efficacy, innovation, risk and competition orientation, entrepreneurial identity, and the outcome of entrepreneurial success [40]. 


\section{Limitations}

Finally, the results must also be viewed in light of their limitations. Given the sample used in the study, it was not possible to control branches and regional areas in the explanation of hypothetical relations. Future research should, for example, include a more representative sample in terms of branches and areas. However, the challenge will be to obtain a representative sample of women entrepreneurs [12]. This study, in which performance was related to entrepreneurial competencies, did not isolate the influence of context from the identified competencies [12]. Although the scores for culture and economic development are comparable between these two countries, the environmental context in Ireland is slightly more conducive to effective entrepreneurial education for women entrepreneurs than that in Germany in terms of the cultural dimension of Gender Egalitarianism Societal Practices and of Society Uncertainty Avoidance Practices [40]. Entrepreneurship education and training programs for women entrepreneurs will be more effective in cultures characterized by promoting gender-egalitarianism, and minimizing uncertainty avoidance [10], so they might be more effective in Ireland than in Germany in terms of these dimensions The concept of competence can be differentiated into an objective and a subjective competence concept [41]: We can define objective competence as performance that can be measured with standardized scales and tests. Subjective competence is related to the subjective assessment of performance relevant characteristics that are needed to meet entrepreneurial demands. Methodologically, performance was inferred from statements in self-assessments by women entrepreneurs. Future studies based on the performance of objective competence would be useful and needed.

\section{Conclusions}

The results of the present study have theoretical and practical implications. This study contributes to the limited previous research on female entrepreneurial competencies and offers a theoretical model of female entrepreneurial competencies, explaining entrepreneurial performance of small enterprises in the innovation-driven economies of Germany and Ireland. Because the current understanding of entrepreneurial competencies of women entrepreneurs as predictors of entrepreneurial success has been incomplete, the objective of the study has been to develop a theoretical model of competencies that predict entrepreneurial success of women entrepreneurs as an essential contribution to constructing more effective training programs and optimizing the selection of women entrepreneurs.

Drawing on the developed theoretical model, both taskrelated skills and broader factors of characteristic adaptations and identity strongly predict entrepreneurial competencies. Characteristic adaptations, such as social-cognitive and motivational, are related to the way how people behave consistently, although the consistency is situation specific. Characteristic adaptations are influenced by traits and by the context. Identity refers to the self-defining life narratives that regulate behavior and give the individual life a unique meaning. The entrepreneurial competencies predict the entrepreneurial performance consisting of the dimensions of economic performance, individual performance and societal contribution enhanced by the dimensions of quality of performance, customer satisfaction and productivity.

The practical implication of the study is that besides skills, characteristic adaptations and identity should also be developed in entrepreneurial education programs targeted at women entrepreneurs of small businesses, although the extent to which task-related skills and characteristics adapations such as entrepreneurial self-efficacy contribute to an enterprise's success seems to be greater than that of identity.

Key areas for future research are the development of theoretical models of competencies that predict entrepreneurial success of different target groups. From an educational perspective such models are of high importance because they inform program design about which competencies should be furthered to enhance entrepreneurial success.

\section{Competing Interests}

The author declares that she has no competing interests.

\section{Acknowledgements}

This project has received funding from the European Union's Horizon 2020 research and innovation programme under grant agreement No 645441. The author would like to thank the European Commission for funding this research and innovation project.

\section{References}

[1] Ahmad, N. \& Hoffman, A. (2007). A Framework for Addressing and Measuring Entrepreneurship Indicators Steering Group. OECD. Paris.

[2] Bandura A (1977). Self-efficacy: toward a unifying theory of behavioral change. Psychological Review, 84 (2), 191-215.

[3] Bartlett, C. A. \& Ghoshal, S. (1997). The myth of the generic manager: new personal competencies for new management roles. California Management Review, 40 (1), 92-116.

[4] Bird, B. (1995). Towards a theory of entrepreneurial competency. Advances in Entrepreneurship, Firm Emergence and Growth, 2 (1), 51-72.

[5] Bollen, K. A. (1990). Overall fit in covariance structure models: two types of sample size effects. Psychological Bulletin, 107, 256-259.

[6] Boyatzis, R. E. (2008). Competencies in the 21 st century, The Journal of Management Development, 27 (1), 5-12.

[7] Boyatzis, R. E. (1982). The competent manager: A model for effective performance. New York: John Wiley \& Sons. 
[8] Brandstätter, H. (2011). Personality aspects of entrepreneurship: A look at five meta-analyses. Personality and individual differences, 51 (3), 222-230.

[9] Brush, C. G., de Bruin, A. \& Welter, F. (2009). A genderaware framework for women's entrepreneurship. International Journal of Gender and Entrepreneurship, 1 (1), 8-24.

[10] Bullough, A, de Luque, M. S., Abdelzaher, D. \& Heim, W. (2015). Developing Women Leaders Through Entrepreneurship Education and Training. Academy of Management Perspectives, 29 (2), 250-270.

[11] Cheng, M. I. \& Dainty, A. R. J. (2003). The differing faces of managerial competency in Britain and America. Journal of Management Development, 22 (6), 527-537.

[12] Davidsson, P. (2016). Researching Entrepreneurship: Conceptualization and Design. New York: Springer.

[13] Davis, M. H., Hall, J. \& Mayer, P. S. (2016). Developing new measure of entrepreneurial mindset: reliability, validity and implications for practioners. Consulting Psychology Journal: Practice and Research, 68 (1), 21-48.

[14] European Commission (2010). Mitteilung der Kommission: Europa 2020. Eine Strategie für intelligentes, nachhaltiges und integratives Wachstum. http://eur-lex.europa.eu/. Accessed 18 November 2016.

[15] Geiser, C. (2010). Datenanalyse mit Mplus. Eine Anwendungsorientierte Einführung. Wiesbaden: Springer VS.

[16] Göbel, S. (1998). Persönlichkeit, Strategien und Erfolg. In M. Frese (Ed.), Erfolgreiche Unternehmensgründer [Schriftenreihe: Wirtschaftspsychologie] (pp. 99-122). Göttingen: Verlag für Angewandte Psychologie.

[17] Gottschalk S. \& M. Niefert (2011). Gender Differences in Business Success of german Start-up Firms. Discussion Paper N. 11-019. Centre for european Research.

[18] Heder, E. \& Ljubic, M. (2013). Entrepreneurial learning Training Needs Analysis for SMEs. South East European Centre for Entrepreneurial Learning. Croatia.

[19] Hu, L., \& Bentler, P. M. (1999). Cutoff criteria for fit indexes in covariance structure analysis: Conventional criteria versus new alternatives. Structural Equation Modeling, 6 (1), 1-55.

[20] Kelley, D., Singer, S. \& Herrington, M. (2016). Global Entrepreneurship Monitor: Global Report 2015. www.gemconsortium.org. Accessed 18 November 2016.

[21] Lerner, M. \& Almor, T. (2002). Relationships among strategic capabilities and the performance of women-owned small ventures. Journal of Small Business Management, 40 (2), 109125 .

[22] Leutner, F., Ahmetoglu, G., Akhtar, R. \& Chamorro-Premuzic, T. (2014). The relationship between the entrepreneurial personality and the Big Five personality traits. Personality and Individual Differences, 63, 58-63.

[23] Lumpkin, G. T. \& Dess, G. G. (1996). Clarifying the entrepreneurial orientation construct and linking it to performance: Academy of Management Review, 21 (1), 135-172.

[24] Makhbul, Z. M. \& Hasun, F. M. (2011). Entrepreneurial Success: An Exploratory Study among Entrepreneurs. International Journal of Business and Management, 6 (1), 116125 .
[25] Man, T. W., Lau, T. \& Snape, E. (2008). Entrepreneurial competencies and the performance of small and medium enterprises: an investigation through a framework of competitiveness. Journal of Small Business and Entrepreneurship, 21 (3), 257-276.

[26] Marsh, H. W., Hau, K-T. \& Grayson, D. (2005). Goodness of Fit Evaluation in Structural Equation Modeling. In A. Maydeu-Olivares \& J. McArdle (Eds.), Contemporary Psychometrics. A Festschrift for Roderick P. McDonald (pp. 276 - 336). New Jersey: Erlbaum.

[27] McAdams, D. P. \& Pals, J. L. (2006). A new big five. Fundamental principles for an integrative science of personality. American Psychologist, 61, 204-217.

[28] McLaughlin, E. B. (2012). An emotional business: The role of emotional intelligence in entrepreneurial success. Dissertation. University of Texas.

[29] Meffert, H., Burmann, C. \& Kirchgeorg, M. (2012). Marketing. Grundlagen marktorientierter Unternehmensführung; Konzepte - Instrumente - Praxisbeispiele (11. überarb. und erw. Aufl.). Wiesbaden: Gabler.

[30] Miller, D. (1983). The correlates of entrepreneurship in three types of firms. Management Science, 29, 770-791.

[31] Mitchelmore, S. \& Rowley, J. (2013). Entrepreneurial competencies of women entrepreneurs pursuing business growth. Journal of Small Business and Enterprise Development, 20 (1), 125-142.

[32] Mitchelmore, S. \& Rowley, J. (2010). Entrepreneurial competencies: a literature review and development agenda. International Journal of Entrepreneurial Behavior \& Research, 16 (2), 92-111. doi: 10.1108/13552551011026995.

[33] Peris Bonet, F., Rueda Armengot, C. \& Galindo Martín, M. Á. (2011). Entrepreneurial success and human resources. International Journal of Manpower, 32 (1), 68-80.

[34] Piacentini, M. (2013). Women Entrepreneurs in the OECD: Key Evidence and Policy Challenges. OECD Social, Employment and Migration Working Papers, No. 147, OECD Publishing. doi: 10.1787/5k43bvtkmb8v-en.

[35] Popkova, O. (2012). The Role of Identity in the Development of Senior Leader Expertise: A Constructive-development Perspective. Master Thesis.

[36] Poudel, K. P. (2014). A discourse on entrepreneurial identity: three essays. Electronic Theses and Dissertations. Paper 1757.

[37] Rauch, A. \& Frese, M. (2007). Let's put the person back into entrepreneurship research: A meta-analysis on the relationship between business owners' personality traits, business creation, and success. European Journal of Work and Organizational Psychology, 16 (4), 353-383.

[38] Rychen, D. S. (2001). Introduction, 1-15. In D. S. Rychen \& L. H. Salganik (Eds.), Defining and selecting key competencies. Göttingen: Hogrefe \& Huber.

[39] Salovey, P. \& Mayer, J. D. (1990). Emotional intelligence. Imagination, Cognition and Personality, 9 (3), 185-211.

[40] Schneider, K. (2017). Promoting the Entrepreneurial Success of Women Entrepreneurs Through Education and Training. Science Journal of Education. 5 (2), 50-59. doi: 10.11648/j.sjedu.20170502.13. 
[41] Sembill, D. (1992). Problemlösefähigkeit, Handlungskompetenz und emotionale Befindlichkeit. Göttingen: Hogrefe.

[42] Splitter, L. J. (2010). Dispositions in education: Nonentities worth talking about. Educational Theory, 60 (2), 203-230.

[43] Stuart, R. \& Lindsay, P. (1997). Beyond the frame of management competenc (i) es: towards a contextually embedded framework of managerial competence in organizations. Journal of European Industrial Training, 21 (1), 26-34.

[44] Unger, J. M., Rauch, A., Frese, M. \& Rosenbusch, N. (2009). Human capital and entrepreneurial success: A meta-analytical review. Journal of Business Venturing, 26, 341-358.
[45] Valencia-Silva, M., Lamolla, L. \& Amorós, J. E. (2014). Current ventures of women entrepreneurs: relating performance and goals. International Journal of Entrepreneurship and Small Business, 22 (3), 378-393.

[46] Wang, C. L. (2008). Entrepreneurial orientation, learning orientation, and firm performance. Entrepreneurship Theory and Practice, 32 (4), 635-656.

[47] Weinert, F. E. (2001). Concept of Competence. A Conceptual Clarification. In D. S. Rychen \& L. H. Salganik (Eds.), Defining and selecting key competencies (pp. 45-65). Göttingen: Hogrefe \& Huber.

[48] Zhao, H., Seibert, S. E. \& Hills, G. E. (2005). The mediating role of self-efficacy in the development of entrepreneurial intentions. Journal of Applied Psychology, 90, 1265-1272. 